\title{
Crisis económica y música popular en Monterrey entre 1970 y 1990
}

José Óscar Ávila Juárez ${ }^{1}$ amorom_99@yahoo.com DOI: https://dx.doi.org/10.31836/lh.20.7106
Economic crisis and popular music in Monterrey between 1970 and 1990

\section{Resumen}

El presente estudio busca acercarse al auge musical en la capital de Nuevo León al calor de la crisis económica que cubrió las chimeneas y los negocios de la entidad. Herederos de una tradición musical, los regiomontanos buscaron formas de paliar los problemas cotidianos y, en medio del bullicio social, activaron los soni-

\section{Abstract}

The present study focuses on the musical boom that took place in the capital of Nuevo León State at the worst stage of economic crisis that turned off the chimneys and faded off businesses. Coming from a musical tradition, the locals looked for ways to alleviate everyday problems, and in the midst of social bustle, they dos provenientes de expresiones locales, nacionales e internacionales, los adaptaron a su cultura y los hicieron suyos a través de sus prácticas sociales derivadas de los bailes. Al final, los habitantes de la urbe construyeron una identidad musical que les sirvió para evadir efímeramente la crisis económica.

Keywords: Popular music, economic crisis, dances, identity and work. Facultad de Filosofía, Universidad Autónoma de Querétaro, México Av. 16 de septiembre 57, Centro Histórico, Santiago de Querétaro, Querétaro, México activated the musical sounds coming from local, national and international expressions; they adapted them to their culture and made their own through their social practices derived from dancing. In the end, the inhabitants of the city built a musical identity that served to evade the economic crisis ephemerally. 


\section{A manera de introducción}

Entender la ciudad de Monterrey es situarse en su larga historia como centro económico, político, social y cultural de una vasta región del Noreste de México. La urbe regiomontana perfiló su estatus actual a partir de que se convirtió en una base industrial de gran envergadura al final del siglo XIX. El proceso de industrialización de Monterrey impactó vastos territorios a la redonda y sometió el espacio a una dinámica social muy concreta que se fue definiendo a lo largo del tiempo. Debido a esos procesos sociales se configuró una ciudad con manifestaciones culturales producto del ir y venir de miles de personas que vieron en ella una esperanza para sobrellevar su cotidianidad.

La revolución alteró momentáneamente las actividades económicas de la capital de Nuevo León, pero no detuvo la extensa socialización abierta por el proceso de industrialización de unas décadas atrás. Más adelante, al compás del país, la entidad norteña se rediseñó debido a los saldos revolucionarios. Durante las décadas de los veinte y treinta, con algunos sobresaltos a consecuencia de una avalancha de demandas sociales (Flores Torres, 1991, pp. 207-259), logró enderezar el rumbo, se repuso de la crisis política y restableció el dinamismo económico (Cerutti, 1993, pp. 51-96). En el decenio de los cuarenta, Monterrey volvió a experimentar un notable desarrollo industrial que determinó en parte su fisonomía urbana contemporánea. Entre 1950 y 1970, la urbe alcanzó una madurez social y cultural alentada por una segunda etapa industrializadora, ${ }^{2}$ la que significó una expansión productiva sin precedentes que atrajo una oleada de miles de personas de diversas partes del país en busca de sustento. A la par de lo que estaba sucediendo en el territorio nacional, la ciudad se vio impactada por diversas transformaciones sociales que incidieron en la conformación de un espacio sui generis sustentado por una historia propia y una serie de valores culturales que fueron modificándose a través del tiempo por las prácticas cotidianas de los habitantes (Zúñiga, 1988, pp. 153-180; Vellinga, 1981, pp. 79-236; Sánchez, 2007, pp. 147-172, y Palacios Hernández, 2007, pp. 207-244).

¿Qué significó esto? Que la urbe regiomontana emergiera en la década de los setenta con características socioculturales singulares derivadas de su proceso productivo, las que se manifestaron especialmente con la irrupción de la crisis económica del periodo. Esta adversa situación dio

La primera la podemos ubicar entre 1890 y 1910, cuando se pusieron en operación fábricas y fundidoras de corte moderno que aplicaron capitales sustanciosos, tecnologías de vanguardia y ocuparon miles de operarios. 
lugar a expresiones de descontento social debido a la carestía y el desempleo sistemáticos, las que fueron encauzadas en varias direcciones por los habitantes de Monterrey; una de ellas fue la dirigida a la concreción de un movimiento musical de corte popular que mediante canciones y bailes sirvió como catalizador para miles de regiomontanos, quienes para amortiguar los sinsabores de la recesión optaron por seleccionar este pasatiempo tradicional y hacerlo suyo socialmente.

Los habitantes de la capital de Nuevo León, acostumbrados a mediar la rutina laboral de múltiples formas, vieron en la música y el baile pasatiempos ideales para distraerse del estancamiento económico y la inflación, los que afectaron drásticamente a la entidad. Entre las décadas de los setenta y ochenta, Monterrey se convirtió en la base organizacional, administrativa y financiera de gran cantidad de agrupaciones musicales procedentes de la zona metropolitana y de varios municipios del estado. Estos grupos, surgidos en el transcurso de la crisis aportaron canciones y ritmos musicales para amortiguar los problemas sociales de miles de regiomontanos. Gracias a su música, constituyeron una oportunidad inmejorable para la convivencia y la distracción.

La aparición de agrupaciones musicales entre 1970 y 1990 supuso un nuevo camino social en la ciudad cimentado por su pasado. Dicho cambio provino de la conformación de una serie de significados culturales emanados de las prácticas de la música, que durante el lapso se erigieron en una especie de contenedor de los problemas cotidianos de los regiomontanos. El intercambio de significados sociales entre los exponentes de la música y los escuchas, a larga, ayudó a reconfigurar la identidad de los habitantes citadinos.

Al entrar la década de los setenta, Monterrey experimentó un sinfín de transformaciones debido a la crisis económica. Sede de un incesante intercambio entre la fuerza de trabajo y el capital, también lo fue de muchas manifestaciones socioculturales que irrumpieron como protesta al estancamiento productivo. La propia efervescencia tradicional de la ciudad se nutrió del intercambio de miles de personas procedentes de otros lugares del país que, huyendo de la crisis, aportaron nuevas interpretaciones identitarias a los oriundos de la capital de Nuevo León. Fundiéndose en un crisol de permanente cambio, estas expresiones alentaron una base cultural defensiva compuesta por las prácticas cotidianas de los habitantes. Esto se evidenció mejor en la escena musical, que de inmediato se convirtió en una opción para canalizar la presión social provocada por la crisis económica, que sin tregua se abatió con dureza sobre la clase trabajadora de la ciudad. De esta manera, los regiomontanos seleccionaron la música para defenderse de sus problemas, y el baile para 
sentirse "alegres" efímeramente y sopesar sus obstáculos cotidianos. Al final del día, ambos elementos los ayudaron a construir estrategias sociales y culturales eficientes para solventar la crisis, y con ello contribuyeron a reconfigurar la identidad local.

\section{La historia y la música popular}

El diálogo entre la Historia y la Música es un constructo social que implica necesariamente tiempo y espacio. Desde hace miles de años el ser humano ha interactuado con los sonidos, lo mismo con los procedentes de la naturaleza que con los que emite él mismo para su deleite. En este caso, entender la práctica musical implica situarla como un elemento de las prácticas sociales en general. Por lo anterior, como parte de mi interés por analizar el boom de música popular en la ciudad de Monterrey entre 1970 y 1990, es relevante definir algunas cuestiones teóricas que ayudan a esclarecer mi propuesta.

Primero, empezamos por deslindar a qué nos estamos refiriendo por música. Según Adolfo Salazar,

la música como arte está basada en el fenómeno acústico que ofrece a la inteligencia los primeros datos suministrados por la materia musical; materia procedente de la selección que el hombre hace entre lo puramente sonoro (Salazar, 1967, p. 7).

Agrega que la percepción de lo acústico ha cambiado en el tiempo, por lo que este último factor más el del espacio, posibilita la invención de la música (Salazar, 1967, p. 8). Al final, arguye que la música es un producto derivado de las propias necesidades sonoras del hombre. Por lo aseverado, podemos manifestar que es el propio ser humano el que da un significado social a la música, requiere de ella y la necesita para solventar sus prácticas cotidianas.

Segundo, también es imperativo aclarar a qué nos estamos referimos con la expresión música popular: es la que escucha el pueblo, o la mayoría de los habitantes de una localidad, una región o un país. Para el caso del Noreste de México, Alfonso Ayala Duarte (2013, p. 287) pondera que la música popular surge de la industria musical creada por la demanda urbana en ciertos contextos. Anota, y esto es importante, que tiene una característica sine qua non: que puede ser comprendida por la mayoría de las personas.

Me interesa aplicar ambas categorías porque me permiten acercarme al proceso social que tuvo la capital de Nuevo León en un lapso donde 
la crisis económica impactó a la mayoría de sus habitantes. Conocer el significado musical de los regiomontanos y su identidad cultural erigida en torno a las prácticas musicales ayuda a comprender sus estrategias de contención y su proceder frente a las adversidades. Por lo mismo, vale la pena ahondar sobre sus necesidades sociales de escuchar música, porque al hacerlo se pone en cuestión la historia de una ciudad y de una población con características culturales sui generis.

La música acompaña al hombre en el tiempo como una manifestación de sus estados de ánimo. Esto no podemos dejarlo de lado, y como muestra hacemos un recordatorio de los juglares de la Edad Media. Al respecto, Johannes Wolf (1965) dice que

se aparecían en los pueblos donde hubiese fiestas para celebrar; en castillos, en ciudades, en aldeas, en ferias y romerías nunca faltaban los juglares, cuya presencia difundía alegría y regocijo en torno (p. 46).

Lo dicho por Wolf refleja la necesidad social de buscar alternativas para relajarnos ante los sucesos cotidianos, sobre todo para eludir aunque sea fugazmente situaciones angustiantes. En este caso, la música es un remedio que ayuda al bienestar de los individuos. Por ende, regresando al caso de Monterrey, una ciudad con una tradición musical relevante, se puede afirmar que este espacio requirió de esos juglares modernos llamados "conjuntos" para entretener y divertir a sus habitantes.

Según Yolanda Moreno Rivas (1989), la música norteña se podría rastrear desde la misma conformación de México a lo largo del siglo XIX. Señala que la guerra de separación de Texas, la guerra con los Estados Unidos y la guerra de Secesión en ese país allanaron el camino para el surgimiento de un género musical basado en la utilización del acordeón. Precisa Moreno Rivas que esta práctica tiene mucho que ver con el estilo del Sur estadounidense, heredero de abundantes rasgos europeos, sobre todo polkas y redovas. Remata que

no habría que perder de vista que la influencia existió en ambas direcciones y el influjo de costumbres y gustos mexicanos prevaleció durante mucho tiempo en los estados sureños recién anexados (p. 57).

Desde la perspectiva propuesta por Yolanda Moreno Rivas, podemos señalar que la tradición musical popular de Monterrey provino de una fusión de prácticas decimonónicas enraizadas por los acontecimientos. Siguiendo esa propuesta, Luis Díaz Santana Garza (2015) considera que Texas ejerció una influencia considerable para el constructo musical del 
Noreste de México, en especial Nuevo León; afirma que debido a la cercanía en el siglo XIX ambos lados conformaron una dinámica zona económica y cultural (p. 65). En esta última parte, Díaz Santana Garza arguye que la tradición musical fue piedra angular del acercamiento, de tal forma que en los dos espacios se construyó una identidad avalada por sus prácticas musicales. También aduce que

en la frontera, escuchar al conjunto y discutir sobre las letras de las canciones y corridos son formas de establecer una identidad norteña, diferente de la identidad centralista, y por lo tanto diferente del mito nacional (p. 67).

Ambos autores, Yolanda Moreno Rivas y Luis Díaz Santana Garza, precisan el derrotero de la música popular que apareció en el Norte-Noreste del país en la centuria decimonónica, aunque hay que precisar que al despuntar la ciudad de Monterrey como un singular centro industrial, marcó una gran diferencia económica en toda la región norteña, y por ende sus procesos sociales fueron delineando caminos musicales que se nutrieron de su efervescencia citadina. Sus desarrollos locales al calor de la revolución y la reconstrucción económica, lo mismo que sus entronques con su industrialización madura de las décadas de los cuarenta a los sesenta, le dieron otro empujoncito para singularizar aún más su estilo musical, de tal manera que a principios de la década de los setenta la ciudad barajó una base musical popular compuesta por tres pilares: uno norteño tradicional, uno moderno con fusiones nacionales y otro moderno con fusiones texanas.

En este entramado por averiguar cómo la música popular se convirtió en un termómetro para medir las prácticas socioculturales de la ciudad de Monterrey en el lapso que va de 1970 a 1990 es importante descifrar el valor de la música en una sociedad determinada. Para ello recurro a Munesuke Mita (1996), quien al hacer una psicología social del Japón moderno manifiesta que

la canción popular es una de las numerosas expresiones del arte popular que establece lo que podríamos llamar patrones expresivos que representan los sentimientos de las masas de una época determinada (p. 31).

Mita opina que la psicología popular requiere de la observación de expresiones, lugares comunes, cargas emotivas, deseos o desesperaciones de las masas populares. Agrega que estas indagaciones ayudarán a entender los sentimientos populares de una época determinada (p. 31). 
La postura de Munesuke Mita es por demás interesante, porque acerca a comprender el auge musical popular que se presentó en Monterrey entre 1970 y 1990. La aparición de un amplio repertorio musical y la comunión de los habitantes en dichas expresiones musicales permiten asumir que en el espacio regiomontano se llevó a cabo un proceso social que tuvo como protagonista la música popular, muestra del carácter social de los pobladores que, al dialogar con los grupos musicales, dejaron ver sus sentimientos hacia el estado de cosas imperante.

De este modo, indagar sobre los sentimientos de los habitantes de la capital de Nuevo León implica conocer las melodías que cantan y bailan. Por lo mismo, lo apropiado es acercarse a la base musical que cobija a los regiomontanos, descifrar las tradiciones musicales en el tiempo que antecede al boom de los decenios de los setenta a los noventa, así como dibujar el proceso musical del periodo para determinar los fundamentos sentimentales al calor de la crisis. Bajo estos parámetros de entendimiento acerca de los sentimientos sociales, Clifford Geertz (2006, p. 93) señala que las actividades religiosas involucran dos disposiciones: estados de ánimo y motivaciones. Para este estudio en concreto de los sentimientos musicales de los habitantes de Monterrey, hay que dilucidar las motivaciones que los hicieron escoger la música como distractora momentánea de la crisis económica. ${ }^{3}$ Para conseguirlo hay que introducirse en el sistema de pensamiento y estilo de vida de la población de la urbe, destacar que la apropiación musical fue un modo sensible de percibir la recesión y de comunicar su malestar por las condiciones sociales imperantes. A través del desahogo y la distracción resultantes de escuchar música y asistir a los bailes, la sociedad regiomontana amortiguó los sinsabores de la crisis. Esta aceptación musical por parte de la mayoría de los habitantes tuvo sus propios significados sociales, económicos, políticos y culturales. El movimiento musical articuló expresiones de descontento social que se pusieron en práctica al calor de las canciones populares y los bailes masivos. Sostenido en parte por las tradiciones locales, este auge musical aglutinó sonidos y géneros de la época y los adaptó a las necesidades culturales de los regiomontanos. La población de Monterrey necesitaba de una esperanza para mejorar su vida cotidiana, y la música fue una solución a sus malestares.

Al final, esta expresión musical echó a volar los sentimientos de los regiomontanos, por ende compraron discos y acudieron a bailar en masa.

Clifford Geertz (2006) afirma que "una motivación es una tendencia persistente, una inclinación permanente a realizar actos y experimentar cierta clase de sentimientos en cierta clase de situaciones" (p. 93). 
La acción determinó una nueva configuración de la música local, que en breve se proyectó como un fenómeno social musical sin precedentes, lo que convirtió a la ciudad de Monterrey en un referente para entender el cambio social y cultural de todo un país sumergido en la crisis económica. La aparición de gran cantidad de agrupaciones locales exitosas sirve para argumentar el diálogo entre los músicos y la sociedad; los primeros ofrecieron un repertorio que distrajo a la segunda de los problemas económicos.

\section{Historia y crisis regiomontana}

La ciudad de Monterrey es un espacio relativamente moderno, producto de la constitución del Estado nacional mexicano y de las coyunturas bélicas que experimentó el país a lo largo del siglo XIX. En este tenor, hablar de la capital de Nuevo León es situarla en el proceso social porfirista de finales de la centuria decimonónica y principios de la siguiente, cuando la industrialización se convirtió en la punta de lanza de la oligarquía local que vio en esta plataforma la oportunidad de cambiar el derrotero económico seguido en la entidad desde antes de la primera mitad del siglo (Cerutti, 1992, pp. 11-54; Zaragoza, 2008, pp. 31-99; y Ávila Juárez, 2012, pp. 23-77). Este sesgo industrial dio protagonismo a la urbe en todo el territorio nacional y la convirtió en un gran centro de transformaciones económicas, sociales y culturales.

La revolución impactó negativamente en la economía y la tranquilidad de los regiomontanos, pero su embestida no detuvo del todo el proceso de cambio gestado durante la industrialización. El conflicto sólo replanteó el camino político a seguir al agotarse el modelo porfiriano. Mientras la elite victoriosa ajustaba el rumbo, el pueblo seguiría su propio dinamismo social y cultural. En el trance, el colectivo buscaría su sobrevivencia y mostraría sus emociones y sentimientos según la circunstancia y su necesidad de esperanza de una mejor vida (Katz, 1999, 317-360; Knight, 2010, pp. 1076-1335).

Al disiparse la guerra civil, el gobierno encauzó las cosas por medio de la Constitución de 1917, cuerpo de leyes que pretendió dar certidumbre a los mexicanos luego del conflicto. En este sentido, lo más importante para los líderes emergentes fue arreglar las finanzas internas del país (Krauze, Meyer y Reyes, 1995, p. 18) y sofocar las rebeliones militares (escobarista y cedillista) y sociales (guerra cristera) producto del ajuste institucional y de las medidas de los gobiernos posrevolucionarios (Meyer, 1994, pp. 95-320).

En medio de los sinsabores económicos y sociales en las décadas del veinte y treinta, hubo intentos por reconfigurar la base económica de 
Monterrey y con esto tranquilizar a la población castigada por el enfrentamiento armado (Rojas Sandoval, 1992, pp. 73-97) Sin embargo, no fue sino hasta el decenio de los cuarenta cuando la urbe pintó una mejor cara económica y su rumbo se enfiló cuesta arriba. La política económica nacional denominada de sustitución de importaciones incidió en la reconversión industrial y propició que la capital de Nuevo León volviera a ser punta de lanza de la economía del país, por lo que su dinamismo productivo atrajo capitales y mano de obra al por mayor, que a la postre la ubicaron en una nueva etapa de su proceso de industrialización (Torres, 1984, pp. 87-108; Ávila Juárez, 2011, pp. 25-60).

El cambio económico debido al desarrollo industrial alteró para siempre la vida de los regiomontanos. A partir del decenio de los cuarenta, Monterrey se convirtió en una verdadera base industrial con proyección nacional e internacional, donde los eslabones productivos de la industria (artículos de consumo, intermedios y de capital) se conjuntaron con los bienes y servicios, unión que logró una verdadera simbiosis con las prácticas sociales de la población. Y, lo más importante, el proceso social que se vivió en la urbe dio origen a una efervescencia cultural sin precedentes que provocó una reconsideración sobre la identidad de los regiomontanos.

El cruce de valores económicos, sociales y culturales moldeó al habitante de la ciudad, que a partir de este momento pasaría a ser considerado por la elite local como trabajador, honrado, responsable y, por si fuera poco, ahorrador, tal como el empresario regiomontano se autocatalogaba en su discurso ideológico reivindicador. Aunque si bien ésta era una expresión etiquetada por los dueños del capital, la reiteración social de esas características a nivel propagandístico (radio y cine) y cotidiano terminaría por convencer a los regiomontanos de su condición de pueblo sui generis, hasta constituirse culturalmente como un caso especial dentro del gran mosaico nacional.

Pero a la par que el empresariado se erigió en portavoz de los habitantes de Monterrey, también emergieron valores provenientes de las prácticas sociales del día a día en una urbe industrial con un vertiginoso cambio. Esos otros ecos procedieron de los boleros, albañiles, barrenderos, zapateros, empleados domésticos, meseros, voceadores, amas de casa, entre otros habitantes de la gran ciudad industrial. En tal contexto de trabajo y supervivencia cotidiana también afloraron prácticas de recreación y diversión, pues no todo fue "vivir para trabajar" en las fábricas, o cumplir con las faenas laborales diversas. Las horas de trabajo se compensaron con idas al parque, al restaurante, al balneario y al cine; o en todo caso a visitar a la familia y preparar la "carne asada" al son del acordeón y el bajo sexto de algún grupo local. 
A lo largo de las décadas de los cincuenta y los sesenta la capital de Nuevo León se convirtió en la ciudad más industriosa de México. La producción de acero, cemento, vidrio y derivados del petróleo la hicieron sobresalir de manera significativa incluso en el contexto internacional. Este dinamismo ocasionó muchos cambios en el interior de la urbe; con el desarrollo económico, Monterrey fue un polo de atracción considerable para individuos deseosos de trabajar y obtener un ingreso permanente. Para 1940 contaba con una población metropolitana de 212353 habitantes; para 1950 contabilizaba 382 021; para 1960 albergaba a 716462 y para 1970 reunía 1266071 habitantes (García Ortega, 1988, pp. 95-98).

Al comenzar la década de los sesenta, la ciudad experimentó una expansión geográfica considerable, extendiéndose a los municipios de San Nicolás de los Garza, Guadalupe y San Pedro Garza García, principalmente. Esta ampliación urbana se debió al arribo de miles de personas en busca de un lugar en las actividades productivas de Monterrey. Sin embargo, este auge se vio frenado a principios de los setenta, cuando la crisis sistémica del capitalismo "coleteó" a México. La caída de los precios del petróleo entre 1973 y 1974 anunció el principio de una recesión cíclica de la economía nacional, de tal manera que en 1976 el peso se devaluó frente al dólar en más del $100 \%$ y siguió un deslizamiento sin control hasta el siguiente decenio. El costo de esta coyuntura para el país fue contundente, al afectar el estancamiento y la inflación a la mayor parte de los hogares mexicanos. La recuperación de los precios del petróleo en 1978 ayudó a compensar la caída, pero la estrategia de contención de la crisis no fue suficiente, y para 1982 una nueva recaída en el valor de los hidrocarburos provocó otra devaluación desenfrenada que deprimió las expectativas nacionales (Ros, 1987, pp.135-152; Pereyra, 2004, pp. 207220; y Ayala, 2013, pp. 19-94). Irremediablemente este estado de cosas repercutió en la actividad económica de Monterrey, espacio industrial y comercial vinculado estrechamente con la economía internacional. Muchas empresas regiomontanas resintieron drásticamente los vaivenes de la crisis, sobre todo, porque las devaluaciones recurrentes afectaron sus finanzas por su endeudamiento en dólares. ${ }^{4}$ A pesar de esto, en 1975 el espacio metropolitano alcanzó los 1576012 habitantes, y cinco años después llegó a la cifra de 1975740 (García Ortega, 1988, pp. 96-97). Como se puede ver, la recesión no impidió la llegada de miles de personas que María de los Ángeles Pozas (2007, p. 91) señala que en 1983 Monterrey alcanzó una tasa de desempleo de 9.8\%, la más alta del país. Agrega que las deudas de los principales grupos empresariales eran las siguientes: ALFA con 2700 millones de dólares, VISA-FEMSA con 2300 millones, VITRO con 600 millones y CYDSA con 400 millones. 
siguieron viendo a la capital de Nuevo León como una esperanza de supervivencia.

Mientras la economía de Monterrey iba en declive, sus habitantes socializaban la crisis mediante el entretenimiento y la diversión. A comienzos de la década de los ochenta, la ciudad se convirtió en una las sedes de vida nocturna más importantes del país. En ese tiempo surgieron centros de espectáculos nocturnos como el Reno Club, El Jaguar, El Zodiaco, Restaurante Charleston, Bar de Gil, Ladies Bar Hawaii, Antonio's, Ladies Bar Camelot, Ladies Bar Gitano, Mil Luces, entre otras opciones. También se abrieron numerosos cines (Elizondo, Bernardo Reyes, Olympia, Encanto, Cinerama 2000, Atenea, Juárez, Florida, Araceli, Reforma, Monterrey, Rodríguez, Principal, Lírico, Azteca, Cinema del Valle, Independencia, Buenos Aires, Río 70, Cuauhtémoc 70, Montoya, Raly, Norma, Chaplin, América, Poza Rica, Anáhuac, Tropical, Cinema 75, Cinema Dorado, entre otros) que significaron una vía para canalizar la evasión de la crisis económica. Otro pasatiempo no menos importante era acudir a los muchos restaurantes familiares y lugares de baile del área metropolitana.

Hay que señalar rotundamente que durante la década de los setenta y al principio del siguiente decenio las atracciones musicales se diversificaron en la ciudad de Monterrey. El arribo de miles de personas procedentes de todos los rincones del estado y del país supuso un nuevo proceso musical que mezcló la tradición con sonidos modernos. A las expresiones nativas se agregaron otras derivadas del intercambio social propio de un espacio receptor de migrantes. Esta mezcla de géneros musicales produjo ritmos novedosos e interesantes para la sociedad regiomontana, sobre todo para la clase trabajadora, que vio en la música y el baile opciones para eludir, aunque fuese de manera momentánea, la crisis económica.

\section{Respuesta a la crisis:}

\section{música y bailes populares}

"Mover el bote", expresión coloquial de la acción del cuerpo al escuchar alguna melodía rítmica, es una actividad necesaria para los que gustan de la música y rinden culto a la diversión y al relajamiento. Desde tiempos inmemoriales el ser humano ha expresado su alegría y emociones vía la música y el baile. Bajo la óptica de la historia, "mover el bote" es una consecuencia temporal de los sentimientos provocados por alguna acción social acústica, mientras que desde la antropología el baile es una forma de expresión y comunicación intencional con símbolos y significados; por su parte, para la sociología el baile es una manifestación de prácticas sociales sobre una base de convivencia estructurada; y con la mirada de 
la psicología, el baile es una apropiación consciente e inconsciente de la realidad. Lo sobresaliente es que estos significados se cruzan en el acto práctico del individuo, donde expresa sus valores culturales y sociales.

Reiterando lo señalado por Munesuke Mita (1996, p. 31), quien afirma que las letras de las canciones populares pueden interpretar lugares comunes, sentimientos intensos, deseos o desesperaciones de las masas, se puede entrever que con las prácticas musicales podemos acercarnos a la mentalidad de una época, aludiendo con esto a casos concretos revisados en Marc Bloch (2006, pp. 93-119 y 502-527) y Carlo Ginzburg (2004, pp. 15-31). Siguiendo el hilo, las letras vienen siendo una expresión sentida de los individuos ante alguna eventualidad social. Lo mismo sucede con el baile, práctica dancística que atestigua un estado de cosas que afecta a los individuos, que expresa tristezas o alegrías. Al final, el baile es una deseosa necesidad de paliar una realidad incómoda al ritmo de la música.

En ese contexto, en el último lustro de la década de los sesenta el país se encontró en la incertidumbre debido al agotamiento del modelo económico. La falta de empleos y de movilidad social, junto con un sistema político represivo (evidenciado a partir de 1968) reventaron la cordura social, pues miles de ciudadanos salieron a las calles a protestar contra el statu quo (antes lo hicieron estudiantes, médicos, maestros y ferrocarrileros bajo otras banderas sociales). Dicho malestar también se tradujo en la creación de organizaciones sociales a lo largo y ancho del territorio nacional para negociar con el gobierno. La continuidad de la crisis en los decenios siguientes y la inoperancia de la clase política nacional tensaron aún más la relación entre la sociedad civil y las autoridades. El temblor de 1985 y la iniciativa ciudadana para ayudar en el desastre reflejaron la fricción de los dos bandos.

Por su parte, la ciudad de Monterrey ha tenido varias miradas de la protesta social. La primera de ellas se presentó en la década de los veinte a consecuencia de las malas condiciones laborales; una segunda se orquestó en el decenio de los treinta contra los postulados cardenistas. Entre las décadas de los cuarenta y los sesenta, la política económica hizo funcionar un dinamismo industrial que calmó las aguas sociales. Las fuertes oleadas de los siguientes decenios hicieron tambalear los cimientos económicos e intranquilizaron a los regiomontanos, pero mantuvieron distancia con respecto a la protesta social. Los habitantes de la capital de Nuevo León tomaron distancia de la efervescencia ciudadana nacional y apelaron a una apuesta pacífica basada en la diversión y la distensión. En este sentido, encumbraron la música y el baile popular para pasar los tiempos aciagos. 
La crisis económica que padeció Monterrey fue terrible; sin embargo, no impidió la llegada de miles de personas en busca empleo. Ante este panorama complicado, los habitantes construyeron una línea imaginaria entre la realidad y la esperanza, y apropiándose de esta última se volcaron a distraerse al por mayor. En ese momento de desesperanza emergieron la música y el baile, artilugios necesarios para evadir de manera efímera los problemas. No era para menos, pues el desempleo y la carestía fueron el pan de todos los días entre los moradores de la ciudad.

Por otro lado, como suele pasar en una sociedad en constante cambio y en un espacio densamente poblado, la música y el baile no fueron las únicas distracciones para los regiomontanos, pues la crisis amplió la gama de pasatiempos. A las diversiones tradicionales (idas al parque, a comer y al cine) se añadió una ventana de ofertas de corte nocturno. También, y es lo más importante para el presente estudio, debido a la aceptación inusitada de la propuesta musical, proliferaron muchos lugares para "mover el bote". De la noche a la mañana se expandió la oferta musical, y con ella gran cantidad de salones de baile (que en otro tiempo fueron lugares de fiestas tradicionales), como el Casino Ferrocarrilero, el Casino San Nicolás, el Casino Nuevo León, el Centro Social la Fama, el Club de Leones de Apodaca, el Casino Aragón y el Casino Panamericano. Y para coronar la lista, la demanda incesante del público obligó a los empresarios musicales a improvisar espacios, entre los que destacó la Exposición Ganadera de ciudad Guadalupe, lugar que daba cabida a casi cien mil personas para oír música y bailar con los grupos del momento, tanto locales como nacionales.

Muchos de los sitios de esparcimiento se veían engalanados por actores y cantantes de la televisión y del cine nacional. La oferta de centros nocturnos se disparó en extremo, los cines locales ofrecían una variada cartelera y los numerosos lugares para convivir y comer lucían llenos en tiempos de crisis. Esta situación de bonanza en los espacios de diversión aparentaba un Monterrey próspero y aislado de la crisis económica que golpeaba al país. Sin embargo, la urbe fue una de las más afectadas por la recesión, aunque por el tamaño de su estructura económica también ofrecía una esperanza para miles que emigraron en busca de un ingreso. Es relevante destacar que no todos aprovechaban la oferta de entretenimiento; la mayoría de los regiomontanos prefería alimentarse que divertirse. A pesar de esto, la ciudad se convirtió en un espacio de relajación importante. ${ }^{5}$

5

En este caso no podemos dejar de lado los procesos sociales que se desarrollaron en otros rincones del país; cada uno tuvo sus propias estrategias de contención de la cri- 
En el caso de los espectáculos de masas, el cine era una opción para los habitantes de la urbe; sus variadas salas proyectaban películas con alta dosis de realidad y, al mismo tiempo, otras cintas con reflejos ficticios propios de la industria. Ambos caminos evidenciaban la crisis económica del sistema capitalista global, con sus ecos políticos, sociales y culturales. Los géneros cinematográficos de comedia, erotismo, fantasía, drama, terror, acción, futurismo entre otros distraían a los regiomontanos y los alejaban momentáneamente de sus problemas cotidianos.

La importancia de la ciudad en el ámbito nacional también se plasmó en el rodaje de varias películas costumbristas. Desde la óptica de productores y directores, Monterrey reunía requisitos cinematográficos para explotar varias temáticas cotidianas. Además, la urbe se erigió como un espacio de crisis, donde la vida se vivía con extraordinario sacrificio. Así, durante la década de los ochenta se filmaron en la capital de Nuevo León las siguientes cintas: Pistoleros famosos (1981), El cazador de asesinos (1983), Los peseros (1983), Silencio asesino (1983), El traficante (1983), El traficante II (1984), Pistoleros famosos II (1986) y Verdugo de traidores (1986). Estos filmes reflejaban una ciudad en crisis donde pistoleros, asaltos, secuestros, asesinos, drogas y violencia eran los temas más representados por los realizadores. Es relevante destacar que casi todas las cintas fueron exitosas. El espectador regiomontano se identificó con la propuesta cinematográfica y concientizó la realidad presentada en la pantalla. Tal como lo señala Pierre Sorlin (1985, p. 33), en el cine hay una representación de la realidad que es digerida por el espectador, que toma conciencia de la imagen en movimiento debido a su ideología y la cultura que lo arropa. ${ }^{6}$ Lo que puede entenderse con esta aseveración de Sorlin es que el público de Monterrey avaló los significados fílmicos, los interiorizó con su vida cotidiana y, al final, los usó para distraerse de la crisis, sin importar la imagen negativa. El cine, como otros pasatiempos, representó opciones para evadir las situaciones complicadas.

Por otro lado, las películas rodadas en la capital de Nuevo León también incluían un variado repertorio musical para captar al espectador. En todas las cintas participaban agrupaciones locales, que en múltiples escenas de cantina hacían bailar a los parroquianos y los llevaban a un momento efímero de alegría y placer. Un ejemplo de esto lo vemos en El cazador de asesinos (1981), filme que contó con la actuación de Los Barón

sis. La historia y la cultura de los mismos espacios definieron el carácter social de sus habitantes.

6

Agrega Sorlin (1985, p. 33) que "el filme sólo persuade porque se conforma a un saber anterior, que en cierta forma viene a identificar". 
de Apodaca, Los Rancheritos del Topo Chico y El Tropical Panamá. De esta manera, el cine como elemento de la cultura popular fue una ventana magnífica para la proyección musical de los grupos regiomontanos. Gracias a este medio la música local se escuchó y difundió más allá de las fronteras estatales, y con ello aumentó la popularidad y las ventas de los grupos radicados en Monterrey. En este tenor, hay que señalar que los productores y directores de los filmes supieron valorar la importancia de la música para los espectadores, un gancho eficaz para "engordar" la taquilla.

En otro orden, hay que señalar que el auge mayor de las agrupaciones musicales se ubica a partir de las décadas de los setenta y ochenta, cuando la misma necesidad de distensión social provocó una demanda musical para el deleite de los escuchas y bailadores. Teniendo como base musical a los representantes de antaño que irrumpieron comercialmente entre 1930 y 1950 (Los Montañeses del Álamo, Los Alegres de Terán, Los Gorriones del Topo Chico, Los Rancheritos del Topo Chico y El Palomo y el Gorrión), en la década de los sesenta surgieron grupos como Los Cadetes de Linares (1960) y Carlos y José (1968), mientras que en el decenio de los setenta lo hicieron Luis y Julián (1973), El Tropical Caribe (1974), Lila y su Perla del Mar (1974), El Tropical Florida (1975), Liberación (1976), Los Barón de Apodaca (1978), El Tropical Panamá (1979) y Los Plebeyos (1979). En la década de los ochenta aparecieron grupos como Los Invasores de Nuevo León (1980), Bronco (1980), Pegasso (1980), Los Mier (1980), Vaquero (1980), Líricos de Terán (1982), Impacto de Montemorelos (1982), entre otros. Estas agrupaciones fueron las más sobresalientes del auge musical que se vivió en Monterrey durante esas décadas. Siguiendo las pautas de sus antecesores, esos nuevos grupos aportaron canciones y ritmos que más adelante se convirtieron en un sello característico de la cultura del oriundo de la capital de Nuevo León.

El vuelo musical de estas agrupaciones constituidas para cumplir con el objetivo de distraer a los trabajadores de la ciudad se concretó con creces al compás de toda una estrategia empresarial para hacer, vender y difundir la música en muchos rincones locales, nacionales e internacionales. Esta ruta posicionó a varios empresarios regiomontanos en el firmamento musical, sobresaliendo entre ellos Servando Cano y Óscar Flores (jefes de las Representaciones Artísticas Serca y Apodaca, respectivamente). Ambos controlaron mayoritariamente el espectáculo de la música popular en Monterrey durante el periodo estudiado.

Pero para proseguir con la afirmación de Munesuke Mita (1996) de que las expresiones musicales son un reflejo del momento anímico de los pueblos, y manteniendo mi postura de que la base musical que surge 
en Monterrey entre 1970 y 1990 obedeció al malestar social ocasionado por la crisis económica, hay que remitirse a un modelo exitoso encarnado por Rigo Tovar. Proveniente de Matamoros, Tamaulipas, y acompañado de su grupo Costa Azul, este cantante marcó una etapa dorada de la música popular mexicana. Aparecido a finales de los sesenta en Houston, Texas, improvisó (al igual que lo hizo su paisano Xavier Passos unos años antes) las "tocadas" de la música tropical con la guitarra y el órgano eléctricos, y tuvo tal éxito que en 1971 su disco Mi Matamoros querido lo catapultó al estrellato. Su camino fue en ascenso meteórico por la urgencia de ídolos en el país. Para 1976, su disco Amor y cumbia lo consagró definitivamente. A las canciones de Mi Matamoros querido, su primer disco, se agregaron "El testamento" y "La sirenita" como las más representativas y populares de su repertorio. Las letras y el ritmo contagioso de sus canciones pusieron a bailar a millones de personas deseosas de distraerse y pasar un rato agradable. Al respecto, Betto Arcos señala que Rigo Tovar, al contrario de José Alfredo Jiménez, es popular porque arma una fiesta en el salón de baile, gozando de su tristeza y bailando la cumbia del desamor (Arcos, 2013, p. 38). Reafirmo lo ponderado por Arcos y agrego que a este sentimiento de escuchar e interpretar las canciones de Rigo se une la escenografía de los oyentes y bailadores, la vivencia en el espacio de la crisis, donde la sociedad busca distracciones para evadir de forma efímera los sinsabores de la vida cotidiana. En este sentido no interesa que la propuesta de Rigo sea una obra de arte, lo que importa es que las letras y los sonidos sumerjan al público en emociones distractoras.

Sin importar la originalidad de su música, lo sobresaliente de Rigo Tovar y su grupo Costa Azul fue integrar la música en el esquema de vida de los mexicanos, es decir, que sus cumbias dieran sentido a su estilo de vida bajo ciertos valores socioculturales. De esta forma, Tovar se constituyó en el primer cantante de grupos musicales de corte popular con convocatoria nacional e internacional. Tanto fue su éxito que de inmediato se rodeó de una pegajosa mercadotecnia para sacar provecho de su popularidad musical. Sus altas ventas discográficas llamaron la atención de los empresarios cinematográficos, quienes capitalizaron el carisma del cantante para promoverlo en películas como Rigo, una confesión total (1979), Rigo es amor (1980), Vivir para amar (1980) y Rigo Tovar, el gran triunfo (1981). Estos filmes le ayudaron a incrementar su éxito y lo proyectaron hasta convertirse en un icono de la música popular mexicana. Con el cantante tamaulipeco se inauguró una nueva etapa en la música nacional, una incluyente y masiva que puso a bailar al país en medio de la crisis económica. 
En lo tocante al auge musical en Monterrey, hay que reconocer que Rigo Tovar y su grupo Costa Azul fueron una influencia notable para muchas de las agrupaciones surgidas en la ciudad durante las décadas de los setenta y ochenta. Además, fue tanta la comunicación del cantante con la urbe que en 1974, en su álbum En la cumbre, incluyó una canción dedicada a la capital de Nuevo León: "Recordando a Monterrey", melodía que la puso en boca de todos en el ámbito nacional. Sin embargo, la conexión memorable de Rigo con Monterrey la vivió el 21 de octubre de 1981, cuando en una presentación masiva reunió cientos de miles seguidores en los terrenos del río de Santa Catarina. En los encabezados del periódico regiomontano El Norte del día siguiente se leía la siguiente nota:

\begin{abstract}
Al ritmo de la música tropical, Rigo Tovar agradece a la multitud reunida en el río Santa Catarina por "ayudarlo a vivir", mientras a su alrededor, entre empujones, polvo, violencia, llanto, euforia y alegría, más de 350 mil personas luchaban por estar cerca de su ídolo. ${ }^{7}$
\end{abstract}

El hecho de haber congregado a tantas personas habla del poder de convocatoria de Rigo en Monterrey, único cantante popular de todos los tiempos que ha reunido una multitud considerable para escuchar y bailar su música. No en balde los regiomontanos empezaban el año de 1981 con penurias económicas, sus principales grupos empresariales se tambaleaban financieramente y los despidos masivos se proyectaban todos los días: por ende, la sociedad local necesitó distraerse, y fue Rigo Tovar el remedio momentáneo a los sinsabores cotidianos.

Otras agrupaciones representantes de la música popular que también influyeron en los grupos de la capital de Nuevo León durante la crisis fueron Los Tigres del Norte, Los Humildes, Ramón Ayala y sus Bravos del Norte, El Renacimiento 74 y Xavier Passos. Todas ellas surgieron entre las décadas de los sesenta y setenta en varios puntos del país y en Estados Unidos y contribuyeron a desarrollar los estilos de los músicos locales. Es menester señalar que el auge de Monterrey no fue único, sino que en otros lugares también aparecieron manifestaciones musicales relevantes que hicieron ola como las primeras expresiones que pusieron a bailar a los mexicanos en medio de la crisis. Aunque por la magnitud y trascendencia del boom surgido en la capital de Nuevo León puede considerarse singular este caso. La aparición de esta base musical en la escena social sigue presente entre los regiomontanos. 
Es un hecho indiscutible que los grupos que conformaron la base en el periodo surgieron como respuesta a la crisis y aportaron distensión para miles de trabajadores que se sintieron identificados con las propuestas. Ya en proceso de diálogo, ambos, músicos y públicos, afianzaron los significados del intercambio, los interiorizaron y construyeron identidades al calor de cientos de melodías. A la postre, las agrupaciones crearon estilos musicales para acercarse a la gente deseosa de pasar un buen rato. Cada fin de semana consagraron tiempo y espacio para entrar en comunión. De esta manera, los bailadores abarrotaron los diversos salones dispersos en el área metropolitana de Monterrey. El ambiente de crisis y búsqueda de esperanza, combinado con la historia y cultura musical local, puso las condiciones para que miles de seguidores enaltecieran las agrupaciones que, empujadas por esa demanda de diversión, hicieron su parte con mucha música y hartos bailes.

\section{Cronología de la crisis y su dosis musical}

Este proceso social de identificación entre la música y la sociedad se dio de manera paulatina, conforme transcurrió la recesión económica. Al arreciar la crisis en 1982, en plena devaluación del peso frente al dólar, estancamiento e inflación galopante, México fue calificado como el país más endeudado del mundo, con una deuda de 64000 millones de dólares que asfixió incesantemente a su población. ${ }^{8}$

Al transcurrir ese año, los problemas sociales se agudizaron a escala nacional. Para los habitantes de Monterrey, ciudad industrial muy dependiente de los vaivenes económicos, las cosas no pintaron mejor. Al concluir mayo de 1982 se anunciaba una escalada de incrementos en la canasta básica: aceite, leche, pan, azúcar, refrescos, café y carne. Igual pasaría con los servicios: transporte, alquileres, servicios médicos, cine y teléfonos. ${ }^{9}$ A pesar de esta terrible situación para los regiomontanos, el gobierno del estado de Nuevo León anunciaba para el 19 de mayo un programa de recreación popular amenizado por Los Cadetes de Linares, Luis y Julián y Movimiento Obrero. ${ }^{10}$ La presentación de estos grupos musicales en medio de la crisis induce a reflexionar sobre la intención de las autoridades de tranquilizar a la población con música y baile.

El 27 de junio del mismo año de 1982 se dio a conocer que los alimentos, las rentas, la ropa y las escuelas de Monterrey eran más caros que en

(24 de abril de 1982). El Norte, Monterrey, p. 1A.

(16 de mayo de 1982). El Norte, Monterrey, pp. 1-3E.

(18 de mayo de 1982). El Norte, Monterrey, p. 8D. 
Guadalajara y la ciudad de México. ${ }^{11} \mathrm{Al}$ día siguiente se anunció que el país enfrentaba la peor crisis financiera de toda su historia. ${ }^{12}$ Una de las consecuencias de la crisis que padecería Nuevo León durante 1982 sería la inseguridad, pues ese lapso registró el deceso de 120 personas abatidas por arma de fuego. ${ }^{13}$

Siguiendo el orden cronológico de la crisis, el 12 de mayo de 1983 el gobierno federal optó por auxiliar a empresas endeudadas, entre ellas las de la ciudad de Monterrey. ${ }^{14}$ Como preludio de la crisis, el 7 de julio la compañía Troqueles y Esmaltes, S.A., anunció la paralización de sus actividades por dos semanas. ${ }^{15}$ Dos días después comenzó el rodaje en la ciudad de la película El silencio asesino (1983), cinta con alta dosis de pasión, violencia y sexo. ${ }^{16}$

Por otro lado, Julián Garza, primera voz del dueto Luis y Julián, señalaba en una entrevista fechada el 26 de julio de 1983 que la música norteña regional tenía una gran penetración entre la gente del campo. Agregaba en esa ocasión que los corridos eran una expresión de la realidad y que algunas canciones norteñas eran para todos los gustos, tanto en lo referente a la posición social del individuo como a lo referente a su lugar de residencia, ya fuese en el ámbito urbano o campirano. ${ }^{17}$

El 23 de septiembre de 1983 se anunciaba que el peso se devaluaría 13 centavos diarios frente al dólar. ${ }^{18}$ Tres días después se señalaba que México recibiría del Banco Mundial un préstamo de 565 millones de dólares para contrarrestar la crisis. ${ }^{19}$ La entrada de 1984 no fue nada alentadora para el país. Aparte, con el fin de obtener créditos para contener la crisis, el presidente Miguel de la Madrid Hurtado (1982-1988) prometía al Fondo Monetario Internacional ajustes para el manejo de la economía interna. ${ }^{20}$ El 9 de enero de ese año se anunciaba un incremento del 100\% al gas usado en los establecimientos industriales. ${ }^{21}$ Mientras tanto, en Monterrey,

\footnotetext{
11 (27 de junio de 1982). El Norte, Monterrey, p. 1E.

12 (28 de junio de 1982). El Norte, Monterrey, p. 6A.

13 (1ํ de enero de 1983). El Norte, Monterrey, p. 13B.

14 (12 de enero de 1983). El Norte, Monterrey, p. 1A.

15 (7 de julio de 1983). El Norte, Monterrey, p. 9A.

16 (9 de julio de 1983). El Norte, Monterrey, p. 4D.

17 (26 de julio de 1983). El Norte, Monterrey, p. 8D.

18 (23 de septiembre de 1983). El Norte, Monterrey, p. 1A.

19 (26 de septiembre de 1983). El Norte, Monterrey, p. 1A.

20 (4 de enero de 1984). El Norte, Monterrey, p. 1A.

21 (9 de enero de 1984). El Norte, Monterrey, p. 1A.
} 
el 21 de enero, la gente se quejaba de los altos precios de la leche, que consideraban un artículo de lujo. 22

En medio de ese difícil panorama económico siguió el transcurrir de los días de la clase trabajadora de Monterrey, que los fines de semana se ponía los pantalones vaqueros, botas y sombrero para asistir a los bailes convocados en las diferentes zonas de la ciudad. Los espacios de baile sirvieron como refugio de la crisis; se acudía a ellos a "mover el bote", pero también para socializar, beber y enamorar. Ése fue el derrotero de buena parte de la sociedad regiomontana, que vio en la diversión social un medio para paliar los estragos de la crisis económica que cayó en la ciudad durante las décadas de los setenta y ochenta.

El año de 1985 comenzó con mucho frío en la capital de Nuevo León, y el 18 de enero se anunciaba que el grupo empresarial regiomontano ALFA reestructuraría su deuda de 880 millones de dólares con 60 bancos internacionales. En la reunión celebrada en Nueva York se señalaría que Chase Manhattan Bank, Citibank, Morgan Guaranty Trust y Bank of America habían llegado a un acuerdo con ALFA, después de tres años de negociaciones. ${ }^{23}$

En medio de la austeridad impulsada por el gobierno de Miguel de la Madrid Hurtado, el 7 de febrero se manifestaba que el Estado mexicano reduciría en 100 mil millones de pesos su gasto público y que bajaría los subsidios y dejaría de invertir en proyectos no prioritarios. En esta ocasión el gobierno anunciaba también que procedería a liquidar, transferir o vender 236 empresas del Estado para enfrentar los problemas, corregir desviaciones y mantener la ruta correcta de la política económica. ${ }^{24}$

En esa situación de incertidumbre, el 9 de febrero de 1985 Federico Caballero, vocalista y líder de la agrupación musical Los Plebeyos, opinaba del éxito de su canción "El Pipiripao". Señalaba Caballero que la melodía hacía alusión a su persona, a quien también le adjudicaban el sobrenombre de "la Guayaba" por las pecas de su cara. Manifestaba que la canción tenía siete meses de exitoso recibimiento en las radios de México y Estados Unidos, que se tocaba hasta en las bodas y las discotecas por pegajosa, pues con "El Pipiripao" la gente se ponía a bailar de inmediato por divertida. Agregaba que el personaje de la rola era un muchacho alegre y amiguero, y que "la canción dice lo que yo quería transmitir, pero más que todo, es una letra alegre para que la gente se sienta bien" ${ }^{25}$

\footnotetext{
22 (21 de enero de 1984). El Norte, Monterrey, p. 1B.

23 (18 de enero de 1985). El Norte, Monterrey, p. 1A.

24 (7 de febrero de 1985). El Norte, Monterrey, p. 1A

25 (9 de febrero de 1985). El Norte, Monterrey, p. 1D.
} 
Por otro lado, seguían los movimientos económicos en el gobierno federal y el 13 de febrero anunciaba la Secretaría de Programación y Presupuesto un reajuste a 35 empresas paraestatales, 27 pertenecientes a la Secretaría de Energía, Minas e Industria Paraestatal, 7 de la Secretaría de Hacienda y Crédito Público y una de la Secretaría de Programación y Presupuesto. La intención era liquidarlas, transferirlas o venderlas. ${ }^{26}$ Mientras tanto, el domingo 17 de febrero tendría lugar en el Casino Ferrocarrilero la presentación del conjunto Pegasso y otras agrupaciones musicales para alegrar y poner a bailar momentáneamente a los regiomontanos. ${ }^{27} \mathrm{El}$ domingo 10 de marzo se anunciaba que el sábado 16 habría un "cañonazo musical" en la Exposición Ganadera de ciudad Guadalupe, donde se presentarían Los Bukis, Los Invasores de Nuevo León, Los Hermanos Barrón, Los Hermanos Mier y los Comodines de Guadalupe. Con un horario pactado de 7 de la tarde a 5 de la mañana y precios de preventa de 800 pesos (mil pesos el día mismo), muchos bailadores se darían cita en ese lugar para distraerse. ${ }^{28}$

El miércoles 8 de mayo el periódico El Norte daba a conocer un estudio sobre los grupos empresariales locales y señalaba que debían la mitad de sus activos al 31 de diciembre de 1984. Que ALFA, VISA, VITRO, CYDSA, CEMEX, LAMOSA e IMSA, debían en conjunto 1.15 billones de pesos a entidades bancarias, sobre todo extranjeras. De todos ellos, ALFA era el más comprometido, pues tenía una deuda de 569.8 mil millones de pesos, el 95\% de sus activos; mientras que VISA debía el $86 \%$, vITRO el $70 \%$ y CYDSA el $48 \%$. Los otros grupos regiomontanos mantenían mejor semblante financiero al deber menos de la mitad de sus activos. Según el estudio, el problema de la deuda se agudizaba al depender de los bancos extranjeros y de la volatilidad de los mercados cambiarios ante la incertidumbre mundial. ${ }^{29} \mathrm{Tal}$ era el terrible panorama económico que amenazaba a esos gigantes industriales de los cuales vivían miles de habitantes de Monterrey.

A pesar del desalentador panorama, el sábado 14 de junio de 1985 habría un gran baile en el Casino Garzablanca, donde se presentarían la Sonora Santanera, Esteban Jordan, José Luis Gazcón y su Banda Huichol, Kiko Montalvo y su conjunto y el grupo Fuego Tropical. Con entradas de 1200 pesos, el horario corrido sería de $7 \mathrm{pm}$ a 5 am. ${ }^{30} \mathrm{El}$ siguiente

\footnotetext{
26 (13 de febrero de 1985). El Norte, Monterrey, p. 3A.

27 (17 de febrero de 1985). El Norte, Monterrey, p. 6C.

28 (10 de marzo de 1985). El Norte, Monterrey, p. 6C.

29 (8 de mayo de 1985). El Norte, Monterrey, p. 8A.

30 (14 de junio de 1985). El Norte, Monterrey, p. 9C.
} 
sábado (22) se programaba otro baile en el mismo lugar, con la intervención de Los Baby's, Los Astros de Linares, Los Internacionales de Durango y Quiquis y su grupo Chévere. ${ }^{31}$ El 29 de junio, nuevamente el Casino Garzablanca sería sede de otro baile, donde amenizarían J.L.B. y Compañía, Tropical del Bravo, Grupo Condado y Los Ángeles de Chávez. ${ }^{32}$ Como se puede observar, esos pasatiempos representaron una distracción sensacional para los regiomontanos. En Monterrey y su área metropolitana proliferaron estos bailes debido a la incesante demanda de diversión, ya que el baile se convirtió en un pasatiempo preferido de los habitantes de la capital de Nuevo León.

Como preludio de lo complicado que iba ser 1986 para los mexicanos, el 17 de enero se anunciaba un programa gubernamental de créditos para la adquisición de alimentos. ${ }^{33}$ Esta noticia significó una burla para la mayor parte de los asalariados del país, quienes siguieron cargando con la crisis. En medio de esa situación lamentable, el mismo día en Monterrey se anunciaba el cierre de dos cines (Chaplin y América) bajo el pretexto de que pasaban películas pornográficas y atentaban contra la moral pública y las buenas costumbres. ${ }^{34}$ La decisión tomada por Luis M. Farías, presidente municipal, sugiere desesperación y autoritarismo oficial. Sin embargo, la orden se cumpliría a medias, por no ser pareja con otros seis cines que también proyectaban pornografía en la ciudad y que pertenecían a la Compañía Operadora de Teatros, organismo paraestatal.

Los estragos de la crisis económica no cesaban, y el 28 de enero se conocía la noticia de que PEMEX y Fundidora Monterrey debían muchos millones de pesos a cientos de pequeños negocios y grandes empresas de Nuevo León. ${ }^{35} \mathrm{Al}$ día siguiente aparecía el encabezado de que la acerera regiomontana adeudaba a 600 empresas. Ante esto, Jaime Carretero Puga, director general de la paraestatal, corroboraba la deuda y anunciaba el pago a los proveedores para las siguientes cuatro o cinco semanas. ${ }^{36}$

Mientras tanto, en el primer informe del gobernador de Nuevo León, Jorge Treviño (1985-1991), el 15 de marzo, congregaría a diez mil personas, y para entretenerlas las autoridades contratarían a Los Rancheritos del Topo Chico y Líricos de Terán, dos agrupaciones musicales locales de

\footnotetext{
31 (22 de junio de 1985). El Norte, Monterrey, p. 9C.

32 (29 de junio de 1985). El Norte, Monterrey, p. 7C.

33 (17 de enero de 1986). El Norte, Monterrey, p. $1 \mathrm{~A}$.

34 (17 de enero de 1986). El Norte, Monterrey, p. 1B.

35 (28 de enero de 1986). El Norte, Monterrey, p. 1 B.

36 (29 de enero de 1986). El Norte, Monterrey, p. 1B.
} 
mucha convocatoria.$^{37}$ La música y el baile fueron componentes necesarios para paliar la crisis Monterrey entre 1970 y 1990.

El 31 de marzo, familias de 25 colonias de la ciudad harían una manifestación contra los excesivos cobros en los recibos de gas y energía eléctrica. ${ }^{38} \mathrm{Y}$ en ese ínter, el 4 de abril se anunciaba la filmación de la película Verdugo de traidores (1986), un filme cargado de escenas violentas que tendría como trama el enfrentamiento de las autoridades con el crimen organizado. Al respecto, Roberto Moreno, productor de la cinta, afirmaba que la ciudad había sido seleccionada como lugar de filmación porque contaba con lugares atractivos como la Cola de Caballo, Chipinque, el parque de la Pastora, los estadios de fútbol y la Monumental plaza de toros. Agregaba Moreno que le había gustado la idea de filmar en la urbe para aprovechar las nuevas avenidas y "tejer" varios enfrentamientos de la policía con narcotraficantes. ${ }^{39}$

En ese contexto de crisis económica seguían los bailes, y el 12 de abril regresaba a la ciudad el grupo Pegasso, después de una exitosa gira por Texas y Florida. La agrupación creada en 1980 se presentaría en el Casino Nuevo León, en Guadalupe, municipio del área metropolitana de Monterrey. ${ }^{40}$ Ese día 12 también se anunciaba que el Holding ALFA había perdido 37399 millones de pesos en 1985, un 714\% más que en 1984, cuando tuvo pérdidas por 4592 millones de pesos. Hasta ese momento el grupo empresarial tenía una deuda de 2500 millones de dólares. ${ }^{41}$

En los pronósticos económicos para el país al concluir 1986, el 18 de abril se señalaba que mientras la población de 1981 a 1986 crecería de 102.6 a 113 millones de personas (un 13\% más), el ingreso por habitante de ese mismo lapso caería de 96.9 a 87.6 pesos ( $12.4 \%$ menos). ${ }^{42}$ Pero seguían los bailes en Monterrey, y para el 24 de abril se presentarían en el Salón Fiesta Casino los siguientes animadores: Rómulo Lozano, Tropical Caribe y Kiko Montalvo. ${ }^{43}$

El 1ํ de mayo se anunció que al estado de Nuevo León le habían aprobado un presupuesto federal de 110 mil millones de pesos, un $78 \%$ más que el asignado para 1985. Entre las cosas que se proyectaban con este dinero, el gobernador Jorge Treviño anunció la ampliación del servicio es-

\footnotetext{
${ }_{37}$ (10 de marzo de 1986). El Norte, Monterrey, p. 1B.

38 (31 de marzo de 1986). El Norte, Monterrey, p. 1B.

39 (31 de marzo de 1986). El Norte, Monterrey, p. 2D.

40 (11 de abril de 1986). El Norte, Monterrey, p. 6C.

41 (12 de abril de 1986). El Norte, Monterrey, p. 3A.

42 (18 de abril de 1986). El Norte, Monterrey, p. 5A.

43 (22 de abril de 1986). El Norte, Monterrey, p. 8C.
} 
tatal de empleo, la construcción de la segunda etapa del Plan Hidráulico, darle más cobertura a la educación y a la salud y, por último, invertir en la creación de infraestructura carretera. ${ }^{44}$

La noticia de las remesas federales fue una mera contención para una noticia bomba que cayó sobre la ciudad de Monterrey con su máximo rigor: el cierre de Fundidora Monterrey. Constituida el 5 de mayo de 1900, la acerera representó el modelo de desarrollo industrial de una urbe, que en los últimos dos decenios del siglo XIX consolidó un proceso industrializador que requirió coronarse con una cereza del pastel, y ésta fue la Fundidora, compañía de grandes proporciones de capital y de muy amplias perspectivas empresariales, que rompió los moldes industriales de la época al situar a la capital de Nuevo León como el primer espacio nacional en propiciar el establecimiento de una siderúrgica integrada (Ávila Juárez, 2012, pp. 29-30). Casa de miles de trabajadores de Monterrey y otros provenientes de muchos lugares del estado y de la República, la empresa dio cobijo y seguridad a los habitantes de la urbe por varias generaciones.

Una compañía de tales dimensiones se mide no por el volumen de capitales que se invirtieron, ni por las toneladas de acero que salieron de sus instalaciones, sino por los ecos culturales y sociales que se construyeron y configuraron en sus espacios laborales, educativos, deportivos, habitacionales y de salud por muchas décadas. Esta compañía sintió el pulso económico de las crisis de 1907 y 1929 y los efectos sociales de la revolución y la guerra cristera. También conoció el camino de la institucionalización para reconstruir la economía nacional y se fortaleció con las políticas denominadas de sustitución de importaciones y desarrollo estabilizador; e igual sufrió con la crisis del sistema capitalista mexicano de las décadas de los setenta y ochenta.

En sus talleres se retrató la ciudad y la vida cotidiana se dejó ver minuciosamente por el trajín diario de sus trabajadores, que acudían a sus labores confiados en su responsabilidad ante la empresa y su familia. A través de sus "ojos" y "oídos", la acería dio cuenta de los problemas sindicales de la década de los veinte y treinta, del esplendor industrial de los decenios de los cuarenta a los sesenta y de las angustias sociales de las décadas de los setenta y ochenta. La economía, la sociedad, la política y la cultura de Monterrey tuvieron una base nodal por 86 años, y ésa fue Fundidora, empresa vinculada fuertemente con la historia de la ciudad.

Al decretarse la liquidación de la acerera el 9 de mayo, también se anunció la cobertura de la crisis sobre la ciudad. Se agregó asimismo el

${ }_{44}$ (1 de mayo de 1986). El Norte, Monterrey, p. 3B. 
colapso financiero de los otros grupos empresariales de la localidad. Esta situación fue el colmo para la sociedad regiomontana, que por años soportó la carga de la crisis.

Todavía dos días antes se publicaba una declaración del diputado minero Arturo Quintanilla Guerra que, consciente de la problemática de la acerera y sabedor de las voces federales de su cierre inminente, pedía al gobierno federal su intervención para absorber la deuda de Fundidora. ${ }^{45}$ Dos días después el gobierno solicitaría a un juez la quiebra de la empresa por considerarla perjudicial para las finanzas del país. Según se desprende de una noticia ventilada inicialmente por un diario de la ciudad de México (El Universal), y recogida por El Norte de Monterrey, la Comisión de Gasto y Financiamiento del Gabinete Económico había determinado la imposibilidad de dar a la acerera regiomontana la cantidad de 90 mil millones de pesos solicitada para sus operaciones en 1986. Además de esto, se agregaba que la empresa representaba una carga a mediano y largo plazo para la nación por la terrible deuda de 360 millones de dólares (190 mil millones de pesos). ${ }^{46}$

Este discurso neoliberal tuvo que ver con los ajustes emprendidos por el gobierno de Miguel de la Madrid Hurtado, quien a su llegada al poder en 1982 se enfrentó a una crisis alimentada por la reducción de los precios del petróleo, principal bastión del ingreso gubernamental. Por medio de la Secretaría de Programación y Presupuesto se dio una lucha incesante para reducir el gasto de las empresas paraestatales, que enfrentadas a los vaivenes de la crisis y a los problemas internos de capitalización y producción, se vieron indefensas ante las decisiones de escritorio del gobierno.

Para el caso de la industria siderúrgica nacional, desde diciembre de 1985, a petición del Banco Mundial, se solicitó al gobierno mexicano un análisis sobre la situación del acero y sus perspectivas futuras. El informe rendido por Fernando Hiriart, en ese entonces director de la Comisión Federal de Electricidad, ponderó una seria crisis financiera en las empresas del Estado, Fundidora Monterrey, Altos Hornos de México y Siderúrgica Lázaro Cárdenas-Las Truchas, y la constituida en la capital de Nuevo León era la más afectada. Hiriart señaló entonces la prioridad de inyectar recursos a las acereras y programar su producción para los mercados nacionales e internacionales. Sin embargo, las soluciones del funcionario no fueron atendidas, y al final el gobierno sólo decidió cerrar Fundidora. Esta decisión sumió en la desesperanza a buena parte de la sociedad regiomontana (Ávila Juárez, 2012, pp. 261-271).

\footnotetext{
45 (7 de mayo de 1986). El Norte, Monterrey, p. 1B.

46 (9 de mayo de 1986). El Norte, Monterrey, p. 1A.
} 
El 10 de mayo aparecería la noticia del cierre. En la ciudad de México se decretaría la inviabilidad de la acerera por parte de la juez Eva María Esteva Mac Master por su precaria situación económica. Se agregaba en la sesión del juzgado civil que la crisis financiera de Fundidora se había consumado por las devaluaciones constantes del peso frente al dólar, las excesivas tasas de interés con respecto al costo financiero de la operación de la empresa y la moratoria de pagos de las obligaciones pendientes a favor de la acería, subrayando la acción de Petróleos Mexicanos. ${ }^{47}$ Ante esto, Arsenio Farell Cubillas, Secretario del Trabajo, informó que el 10 de mayo a partir de las 10:00 horas dejaría de operar la compañía, dejando en el paro a 4600 trabajadores sindicalizados y 2500 trabajadores de confianza, ${ }^{48}$ eso sin contar con los otros miles de trabajadores de sus 35 filiales repartidas en el país.

La decisión del gobierno de cerrar Fundidora planteaba varias interrogantes: si fue para sanear las finanzas nacionales y encaminar a la modernidad industrial al país ante un mundo en transición capitalista; si fue por el triunfo de la ideología económica de un grupo de funcionarios gubernamentales sin apego al Estado en la economía, o si fue por la presión del Banco Mundial de liquidar, transferir o vender las compañías paraestatales a cambio de créditos para reestructurar las finanzas de México. El asunto es que la elección de liquidar al elefante de acero regiomontano afectó a la ciudad de Monterrey y sus habitantes al cerrar una fuente importante de empleo.

El domingo 11 de mayo amanecerían cerradas las instalaciones de Fundidora. Un frío emocional se apoderó de los trabajadores. El secretario de actas del sindicato minero de la sección 67, Juan García Argüelles, indignado manifestaba que habría un estallido social por quitarles el sustento a los representados. ${ }^{49} \mathrm{El}$ lunes 12 se daría un pronunciamiento para luchar por la apertura de la acerera. ${ }^{50}$

La situación de los mineros y empleados de Fundidora se convirtió en una causa regiomontana. El apoyo de la sociedad de Monterrey fue masivo por la identificación con la compañía. Desde la ciudad de México se fraguó el destino del país con medidas de austeridad económica y racionalidad financiera. Y en este contexto de crisis se celebró el Mundial de Fútbol en tierras nacionales.

\begin{tabular}{l|l}
47 & (10 de mayo de 1986). El Norte, Monterrey, p. 1A. \\
48 & (10 de mayo de 1986). El Norte, Monterrey, p. 1A. \\
49 & (11 de mayo de 1986). El Norte, Monterrey, p. 2B. \\
50 & (12 de mayo de 1986). El Norte, Monterrey, p. 1B.
\end{tabular} 
El 12 de mayo, Napoleón Gómez Sada, líder nacional del sindicato minero, señalaba que la mala administración y la corrupción habían sido las causantes de la quiebra de Fundidora. Agregaba que buscaría entrevistarse con Arsenio Farell Cubillas, Secretario del Trabajo, para pedirle la reapertura de la acerera regiomontana. ${ }^{51}$ Mientras tanto, el gobernador Jorge Treviño afirmaba que el cierre era irreversible. ${ }^{52} \mathrm{Y}$ en voz de los trabajadores se anunciaba que más de 5000 mineros y sus familias saldrían a manifestarse en las calles de Monterrey por su causa. ${ }^{53}$

En esto, se manejaba la noticia de abrir la empresa luego de una reunión convocada por Guillermo Bécker Arreola, director de SIDERMEX (el corporativo acerero paraestatal), Gómez Sada y los representantes sindicales de Fundidora y Aceros Planos (secciones 67 y 68, respectivamente). ${ }^{54}$ Sin embargo, esta propuesta fue una especie de medida desesperada, pues desde finales de 1985 el destino de la compañía estuvo echado por su mala situación financiera. Bécker Arreola fue el funcionario seleccionado para reorganizar las compañías y prepararlas para cerrarlas, transferirlas o venderlas, según lo estipulado en el Informe Hiriart. Por ende, la reunión sólo se llevó a cabo como una estrategia para evitar problemas con los mineros.

La lamentable situación laboral en la ciudad afloró al paso de los días después del cierre de Fundidora. En el ínter, cerraron talleres y negocios proveedores de la acerera. El 15 de mayo, aproximadamente veinte mil personas saldrían a protestar por el cierre ${ }^{55}$ Los días pasaron y los mineros siguieron con la esperanza de ser escuchados por el gobierno. En este dilema laboral, los mineros de la sección 68 estaban convencidos que reanudarían actividades. ${ }^{56}$

El 19 de mayo nuevamente se registraría una manifestación de alrededor de 15000 individuos pidiendo la reapertura de la acerera y rechazando el mundial de fútbol. ${ }^{57}$ Para el 21 de mayo se declaró formalmente la quiebra al publicarse la resolución oficial en el boletín judicial del Tribunal Superior de Justicia del Distrito Federal. ${ }^{58}$ Con esta acción se disipaba la posibilidad de una reversa al cierre de Fundidora.

\footnotetext{
51 (13 de mayo de 1986). El Norte, Monterrey, p. 2A.

52 (13 de mayo de 1986). El Norte, Monterrey, p. 1B.

53 (13 de mayo de 1986). El Norte, Monterrey, p. 13B.

54 (15 de mayo de 1986). El Norte, Monterrey, p. $1 \mathrm{~A}$.

55 (16 de mayo de 1986). El Norte, Monterrey, p. 1B.

56 (18 de mayo de 1986). El Norte, Monterrey, p. 8B.

57 (20 de mayo de 1986). El Norte, Monterrey, p. 1B.

58 (22 de mayo de 1986). El Norte, Monterrey, p. 3A.
} 
Mientras tanto, el 22 de mayo, la Secretaría de Comercio y Fomento Industrial, anunciaba un incremento del $90 \%$ de la tortilla, que pasaba de 45 a 80 pesos, y un $115 \%$ del pan que se incrementaba de 8 a 19 pesos. ${ }^{59}$ Con estas acciones nuevamente se volvió a golpear el bolsillo de la gente más desfavorecida del país.

El 30 de mayo sería el día indicado para que los trabajadores de la compañía pasaran a recoger su liquidación. ${ }^{60}$ En medio de esto se anunciaba un panorama laboral sombrío para la ciudad de Monterrey; se calculaba que para fines de 1986 tendría 80000 personas sin empleo, un $10 \%$ de la fuerza de trabajo activa de la entidad, 50000 personas más que en 1985. ${ }^{61}$ Este pronóstico era consecuencia del cierre de Fundidora y de muchos talleres y establecimientos comerciales que dependían del acero. Mientras tanto, el sábado 31 de mayo empezaba el Mundial de Fútbol, organizado por un país en crisis, una crisis que no fue más que la consecuencia de los muchos errores gubernamentales arrastrados desde la década de los setenta, los cuales se agudizaron por la inoperancia oficial en el decenio de los ochenta. El gobierno neoliberal encabezado por Miguel de la Madrid Hurtado apostó por la celebración futbolera para traer bonos económicos, y al mismo tiempo para distraer a la sociedad. Con esta solución, nuevamente volvió a vender cuentas de vidrio a los mexicanos.

En balance, el cierre de Fundidora fue lamentable para los regiomontanos, tomando en cuenta los 86 años de historia paralela con la de la ciudad de Monterrey. Para paliar la medida se aprovechó el Mundial de Fútbol y se ampliaron otras distracciones locales, entre ellas la música y el baile. El problema laboral de la acerera fue contenido eficazmente por el gobierno en sus instancias locales y federales. Las liquidaciones dieron carpetazo a la protesta, que fue regulada por las autoridades para que no se desbordara. Aunada a esto, se dio una circunstancia que ayudó a evitar manifestaciones: que la urbe ofreció alternativas de trabajo. Además, otro factor que influyó en la contención social fue el discurso empresarial regiomontano, ya que sus dirigentes se encargaron de correr la voz para liquidar compañías estatales como Fundidora. Este apoyo privado para cerrar al elefante de acero se dio mientras los corporativos de la ciudad de Monterrey eran auxiliados por el Estado para evitar su quiebra. De esta forma, las autoridades, al aplicar sus medidas económicas, ayudaron deliberadamente a sobrevivir a algunos grupos empresariales y, con esto, amortiguaron los efectos sociales y económicos del cierre de la acerera.

\footnotetext{
59 (22 de mayo de 1986). El Norte, Monterrey, p. 1A.

60 (28 de mayo de 1986). El Norte, Monterrey, p. 1A.

61 (28 de mayo de 1986). El Norte, Monterrey, p. 9A.
} 
A pesar del acontecimiento que cimbró a la sociedad regiomontana, la música y el baile siguieron presentes para distraer a los miles de trabajadores, quienes al elegirlos los convirtieron en pasatiempos favoritos y necesarios frente a la crisis económica. En 1988 se inauguró una nueva etapa del neoliberalismo en México con la llegada a la presidencia de Carlos Salinas de Gortari (1988-1994), quien encabezó un gobierno empeñado en privatizar empresas estatales y apoyar la apertura de mercado mexicano al exterior. Mientras tanto, los habitantes de Monterrey siguieron laborando y divirtiéndose. Precisamente durante el segundo lustro de la década de los ochenta la euforia musical se disparó aún más, abarcando a la región, el país y el extranjero.

\section{Conclusiones preliminares}

La música popular surgida en las décadas de los setenta y ochenta en la ciudad de Monterrey fue alentada por la crisis económica que se abatió sobre la sociedad en general, aunque castigó con más fuerza a la clase trabajadora regiomontana. Su conexión con la práctica musical significó para los trabajadores una forma efímera de evadir la carestía y el desempleo.

Por otro lado, la proliferación de grupos musicales fue una señal evidente del sentir de la sociedad frente a la recesión. Apelando a valores musicales tradicionales, los habitantes de la urbe construyeron campos de significación escuchando melodías y acudiendo a los bailes. El ambiente de crisis fue propició para la demanda y la oferta musicales. Conforme se sucedían las adversidades, surgió una exigencia popular complacida por géneros y ritmos musicales que empezaron a caracterizar a las agrupaciones, que siguieron renovándose al compás de la recepción del público. El resultado fue un proceso sociocultural que se manifestó en el éxito y la trascendencia de los músicos, pero también en la construcción de valores identitarios de sus seguidores, quienes al oír los discos y acudir a los bailes configuraron estilos de vida que se fundieron en todas sus prácticas sociales de lo cotidiano. De esta forma, la práctica musical ayudó a moldear al regiomontano, un molde que se renovó constantemente y se ajustó al ritmo de los acontecimientos.

$\mathrm{Al}$ arreciar la crisis, la música ayudó a construir puentes socioculturales para evadir los sinsabores, una especie de contención emocional a la crisis que se manifestó de lleno en los mensajes musicales y en la convivencia en los bailes. De esta forma, los habitantes de la urbe eludían momentáneamente los efectos de la crisis, y lo hacían escuchando, bailando, hablando, cortejando, conversando, gritando, llorando, peleando entre otras emociones sociales y culturales. 
Una muestra del valor de la música para calmar a los individuos en una sociedad irritada lo podemos ver en la actitud de los regiomontanos ante la crisis económica. Apelando a su historia y cultura, conforme avanzó el declive y aumentó el costo de la vida, ellos se empeñaron construir alternativas de distensión. El pasatiempo musical les amortiguó emocionalmente los estragos, los levantó al darles una esperanza. Esto se puede ver con el ejemplo del cierre de Fundidora, pues a pesar de las enormes pérdidas que trajo la caída del elefante de acero y las manifestaciones para su reapertura, no incidió en el ánimo de la mayoría. Los regiomontanos, envueltos en un proceso social amplio con alternativas laborales, optaron por mantener la calma y sumirse en el trabajo y en sus formas de distracción, entre las que sobresalió su dedicación a escuchar y bailar música popular.

Para concluir, es menester señalar los faltantes en el diálogo propuesto entre la historia y la música. Esta primera aproximación dibuja a grandes rasgos una problemática económica, social y cultural que tiene como centro el movimiento de música popular surgido en la ciudad de Monterrey entre 1970 y 1990. En el estudio se plantean algunos aspectos que confluyeron en el proceso histórico, buscando aclarar una problemática que un muchos sentidos puede ser compleja y en otros simple, dependiendo de nuestros alcances epistemológicos. Por lo mismo, aclaro que hay muchos faltantes para descifrar los entornos histórico-musicales que cubren mi propuesta. Sigo en la búsqueda de puentes de conocimiento teórico-metodológico que me acerquen a mis objetivos académicos. La pesquisa también prosigue en el afán de encontrar las fuentes directas de la música popular del tiempo y espacio analizados, por lo que este acercamiento no cierra las puertas del conocimiento, sino que las abre aún más, ya que conforme avanza integra más elementos que siguen mostrando pistas de una investigación fascinante y con mucha cuerda.

\section{Hemerografía}

Periódico El Norte, 1980-1988.

\section{Bibliografía}

Arcos, B. (2013)

Recordando a mi hermano con las canciones de Rigo Tovar. En C. Rivera Garza (coord.), Rigo es amor. Una rocola a dieciséis voces. México: Tusquets.

Ávila Juárez, J. O. (2011)

Acero, nacionalismo y neoliberalismo en México. Querétaro: Universidad Autónoma de Querétaro. 
Ávila Juárez, J. O. (2012)

Ascenso y caída del elefante de acero regiomontano. Historia de la Fundidora de Fierro y Acero de Monterrey, 1900-1986, Querétaro: Universidad Autónoma de Querétaro.

Ayala Duarte, A. (2013)

Un siglo de música popular (1900-2000). En L. M. Garza Gutiérrez (coord.). Bibliografía de las Artes de Nuevo León, t. II, Artes escénicas. Monterrey: Consejo para la Cultura y las Artes de Nuevo León.

Bloch, M. (2006)

Los reyes taumaturgos. México: Fondo de Cultura Económica.

Cerutti, M. (1992)

Burguesía, capitales e industria en el norte de México. Monterrey y su ámbito regional (1850-1910). Monterrey: Alianza Editorial-Universidad Autónoma de Nuevo León.

Cerutti, M. (1993)

Industria pesada y reconstrucción económica. La Fundidora de Fierro y Acero de Monterrey (1917-1930). En México en los años 20. Procesos políticos y reconstrucción económica. México: Claves Latinoamericanas, Universidad Autónoma de Nuevo León.

Díaz Santana Garza, L. (2015)

Historia de la música norteña mexicana. México: Plaza Valdés Editores.

Flores Torres, O. (1991)

Burguesía, militares y movimiento obrero en Monterrey, 1909-1923.

Monterrey: Universidad Autónoma de Nuevo León.

García Ortega, R. (1988)

El área metropolitana de Monterrey (1930-1984). En M. Cerutti (ed.). Monterrey, siete estudios contemporáneos. Monterrey: Universidad Autónoma de Nuevo León, pp. 95-151.

Geertz, C. (2006)

La interpretación de las culturas. Barcelona: Gedisa.

Ginzburg, C. (2004)

El queso y los gusanos. El cosmos según un molinero del siglo XVI.

México: Océano.

Katz, F. (1999)

Pancho Villa. México: Era.

Knight, A. (2010)

La Revolución mexicana. México: Fondo de Cultura Económica.

Krauze, E., J. Meyer y C. Reyes (1995)

Historia de la Revolución mexicana, 1924-1928. La reconstrucción económica. México: El Colegio de México. 
Meyer, J. (1994)

La Cristiada, t. I. México: Siglo XXI.

Mita, M. (1996). Psicología social del Japón moderno. México: El Colegio de México.

Moreno Rivas, Y. (1989)

Historia de la música popular mexicana. México: Alianza Editorial, Consejo Nacional para la Cultura y las Artes.

Palacios Hernández, L. (2007)

Consolidación corporativa y crisis económica en Monterrey, 1970-1982.

En I. Ortega Ridaura (coord). Nuevo León en el siglo Xx. La industrialización del segundo auge industrial a la crisis de 1982. Monterrey: Fondo Editorial de Nuevo León, pp. 207-244.

Pereyra, C. (2004)

Efectos políticos de la crisis. En P. González Casanova y H. Aguilar Camín (coord). México ante la crisis. El impacto social y cultural. Las alternativas. México: Siglo xxI, pp. 207-220.

Pozas, M. A. (2007)

Las grandes empresas regionales frente a la economía global: dos décadas de adaptación y cambio. En V. López Villafañe (coord). Nuevo León en el siglo Xx. Apertura y globalización. De la crisis de 1982 al fin de siglo. Monterrey: Gobierno del Estado de Nuevo León, pp. 87-127.

Rojas Sandoval, J. (1992)

Monterrey: poder político, obreros y empresarios en la coyuntura revolucionaria. Monterrey: Universidad Autónoma de Nuevo León.

Ros, J. (1987)

La crisis económica: un análisis general. En P. González Casanova y H. Aguilar Camín (coord). México ante la crisis. El contexto nacional y la crisis económica. México: Siglo xxI, pp. 135-152.

Salazar, A. (1967)

La música. México: Fondo de Cultura Económica.

Sánchez, J. A. (2007)

Movimientos sociales en Monterrey. En I. Ortega Ridaura (coord). Nuevo León en el siglo xx. La industrialización del segundo auge industrial a la crisis de 1982. Monterrey: Fondo Editorial de Nuevo León, pp. 147-172.

Sorlin, P. (1985)

Sociología del cine. La apertura para la historia del mañana. México: Fondo de Cultura Económica.

Torres, B. (1984)

Historia de la Revolución Mexicana, 1940-1952. Hacía la utopía industrial. México: El Colegio de México. 
Vellinga, M. (1981)

Industrialización, burguesía y clase obrera en México. México: Siglo XXI.

Wolf, J. (1965)

Historia de la música. Barcelona: Labor.

Zaragoza, A. M. (2008)

La elite de Monterrey y el Estado mexicano, 1880-1940. Monterrey: Fondo Editorial Nuevo León.

Zúñiga, V. (1988)

Migrantes rurales en la ciudad. Éxodo rural, división del trabajo y familia en Monterrey. En M. Cerutti (ed). Monterrey. Siete estudios contemporáneos. Querétaro: Universidad Autónoma de Querétaro, pp. 153-180. 